\title{
Cultural, Material, and Psychosocial Correlates of the Socioeconomic Gradient in Smoking Behavior among Adults
}

\author{
Karien Stronks, Ph.D., ${ }^{1}$ H. Dike van de Mheen, M.A., Caspar W. N. Looman, M.Sc., and \\ Johan P. Mackenbach, Ph.D., M.D. \\ Department of Public Health, Erasmus University Rotterdam, P.O. Box 1738, 3000 DR Rotterdam, The Netherlands
}

\begin{abstract}
Background. The aim was to identify the correlates of educational differences in smoking among adults.

Methods. We used data from the baseline of a Dutch longitudinal study, relating to a population of 2,462 respondents, ages 25-74. Logistic regression was used to assess the educational gradient in smoking. Current smokers were compared with former and never smokers, respectively.
\end{abstract}

Results. The risk of being a current smoker compared with being a former/never smoker was higher among lower educational groups. For example, the odds of being a current smoker compared with never smoker among persons in the lowest level was more than five times as high as that for persons in the highest level. A substantial part (20-40\%) of the increased risk of being a smoker among lower groups appeared to be associated with adverse material conditions. The financial situation especially accounted for that effect. One of the cultural factors, i.e., locus of control, was found to account for approximately $30 \%$ of the educational gradient in the case in which smokers were compared with former smokers. Psychosocial factors, i.e., neuroticism and coping styles, accounted for less of the gradient in smoking than cultural and material factors.

Conclusions. On the basis of the results, we hypothesize that both cultural and material factors contribute to the higher smoking rates among lower socioeconomic groups. Psychosocial factors seem to be less important. If our results are confirmed in more powerful studies, this would indicate, first, that possibilities for a reduction of smoking differences may be found in tailoring smoking cessation programs to the more externally oriented locus of control and the coping styles that are common among lower educational groups, and second, that a reduction of smoking differences may follow from an improvement of the material living

\footnotetext{
${ }^{1}$ To whom correspondence and reprint requests should be addressed at present address: Institute of Social Medicine, Academic Medical Centre, University of Amsterdam, Meibergdreef 15, 1105 AZ Amsterdam, The Netherlands. Fax: 020 6972316. E-mail: k.stronks@amc.uva.nl.
}

conditions of lower socioeconomic groups. ๑ 1997 Academic Press

Key Words: educational status; smoking; risk factors.

\section{INTRODUCTION}

After a period in which smoking was a habit of people within all socioeconomic strata, the percentage of smokers has declined faster among higher socioeconomic groups. This trend has been observed in many countries, including the Netherlands [1-3]. As a result, in industrialized countries smoking is now more prevalent among lower socioeconomic groups. The uneven distribution of this risk factor is likely to make a substantial contribution to the higher prevalence of health problems and the higher mortality rates among lower socioeconomic groups. This has been confirmed in several studies, most of which aimed at the explanation of socioeconomic inequalities in heart disease [4-6].

This suggests that socioeconomic inequalities in health could partly be prevented by reducing the proportion of smokers among the lower socioeconomic strata, e.g., by means of health education programs. However, if policy measures are to be effective, they should consider the reasons for the higher smoking rates. For example, if the higher rates among people in disadvantaged positions are due to adverse material conditions, health education campaigns are not sufficient to reduce the proportion of smokers. They should be supplemented with measures that aim to improve the living conditions of these groups. Knowledge of the background of socioeconomic differences in smoking is therefore crucial for the design of policy measures aimed at the reduction of socioeconomic inequalities in health. Although such differences have been frequently described, less attention has been paid to finding an explanation for this social pattern [7]. In this paper, we will try to identify the cultural, material, and psychosocial correlates of socioeconomic differences in smoking among adults.

When thinking about the explanation for the social pattern of smoking, a cultural explanation is probably 
the first to arise, as members of a particular socioeconomic group are seen as sharing a certain culture [8-10]. In other words, values, beliefs, orientations, knowledge, etc., are features that vary between individuals from different socioeconomic groups. Socioeconomic differences in orientation toward health-related behavior have been the subject of many studies [1114]. As such differences have been shown to be related to smoking, they may account for some of the differential distribution of this risk factor.

One example of a concept frequently applied in this context is "locus of control," which refers to the belief that a person has control over his or her own life. A person with a more internal locus of control believes that he or she is able to influence his or her health by engaging in health-promoting activities or avoiding health-damaging activities. Internal locus of control has been shown to be negatively related to smoking and to be more common among those in higher socioeconomic groups [14-17].

Access to material resources is a second component of the socioeconomic position of an individual. As unfavorable material conditions may "promote" smoking, they probably explain part of the social pattern of smoking. Examples of such conditions are material deprivation and living and working conditions. Evidence regarding the association between these factors and smoking can be found particularly in the British literature $[14,18,19]$. For example, in a study among working-class women, Graham [20] shows that the percentage of women who can hardly afford any necessities is more than three times as high among heavy smokers than among those who had never smoked.

The most obvious link between material factors and behavior is probably one in which material conditions limit the possibilities to engage in healthy behavior, e.g., when one cannot buy healthy food because of financial restrictions [21,22]. This mechanism does not seem to be applicable to smoking, however, as the cheapest choice (not smoking) is also the healthiest. Instead, smoking might be linked to disadvantaged conditions by a coping mechanism [23-25]. People may engage in smoking as a coping behavior when confronted with the stress of disadvantaged circumstances. This may explain why smoking is more prevalent among the lower socioeconomic strata. Such a link between material conditions and smoking is closely connected to psychosocial factors. In studies on socioeconomic differences in behavior, psychosocial factors have thus far received little attention. It is hypothesized that people in lower socioeconomic groups are more frequently exposed to stressful events or circumstances (e.g., life events) or are less well equipped to cope with that stress because of differences in coping resources (e.g., coping styles, social support, personality) [26]. As both stressors and coping resources have been shown to be related to smoking [15,27-29], this may lead to higher smoking rates among the lower socioeconomic strata.

Given their association with both smoking and socioeconomic status, cultural, material, and psychosocial factors as mentioned above are likely to account for the higher smoking rates among lower socioeconomic groups. This may be depicted as shown in Scheme 1.

In this study we will examine the potential importance of cultural, material, and psychosocial factors for the generation of socioeconomic differences in smoking, by identifying the correlates of these differences. We used cross-sectional data from the baseline data collection of a Dutch longitudinal study. The cross-sectional data obviously will not permit conclusions as to the causal determinants of the higher smoking rates in lower socioeconomic groups. Yet given the scarcity of empirical evidence on the background of this phenomenon, an examination of the cross-sectional correlates of these differences can provide useful clues as to the potential importance of explanatory factors. These should be tested in more powerful data sets. As the correlates of becoming a smoker may differ from the correlates of smoking cessation, we carried out two separate analyses, contrasting current smokers with never and former smokers, respectively.

\section{DATA AND METHODS}

\section{Population}

Data were obtained from the baseline data collection of the Longitudinal Study on Socio-Economic Health Differences (LS-SEHD). This is a prospective cohort study that aims to explain socioeconomic inequalities in health in the Netherlands. The design and objective of this study have been described elsewhere in detail [30]. It is based on a cohort of 15- to 74-year-old, noninstitutionalized people with Dutch nationality, in a region in the Southeast of the Netherlands (the city of Eindhoven and a number of surrounding municipalities). An aselect sample of approximately 27,000 people was drawn from the population registers, stratified by age (45- to 74-year-old people were overrepresented) and postcode (overrepresenting the highest and lowest socioeconomic group). In 1991, people in this sample received a postal questionnaire. This questionnaire contained questions on (among others) smoking habits

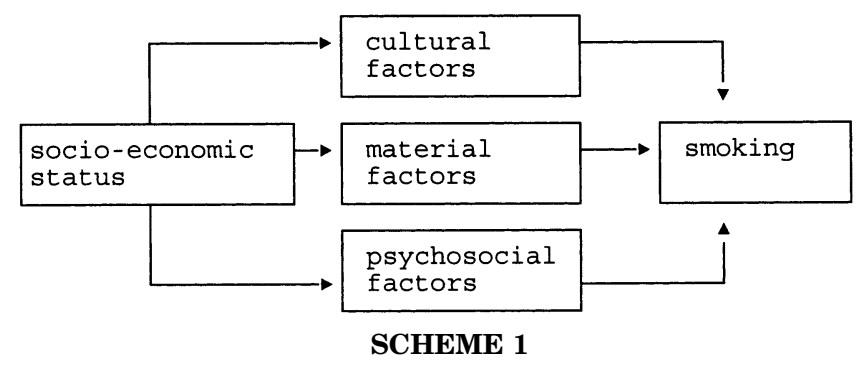


and socioeconomic status. The response rate was $70.1 \%$. A (random) subsample of approximately 3,500 persons was drawn from those who responded to the postal questionnaire. This subsample was approached for a more extensive oral interview. Most of the determinants of smoking were requested in this interview. The response rate was $79.4 \%$, resulting in a study population of 2,802 respondents. The analyses presented in this paper were based on the population that participated in this oral interview. As the aim was to identify correlates of smoking differences in the adult population, people 25 years and older were selected for these analyses $(n=2,462)$.

Nonresponse analyses suggest that the population considered in this study closely resembles the original sample. First, differences in response to the postal questionnaire between socioeconomic groups and other subgroups were relatively small (e.g., $67 \%$ response in the lowest socioeconomic group to $73 \%$ response in the highest socioeconomic group, as indicated by postcode). Moreover, a small sample of those who did not respond to the postal questionnaire $(n=239)$ was approached for a nonresponse interview. Respondents to this interview did not significantly differ from the respondents to the postal questionnaire with respect to socioeconomic characteristics such as the source of income or the presence of financial problems [31].

Second, differences in response to the oral interview were small, too. Moreover, as both educational level and smoking have been measured in the postal questionnaire, we were able to check whether the socioeconomic distribution of smokers among those participating in the oral interview was similar to that for the whole study population. We observed a similar pattern of current, never, and former smokers among educational levels, although differences were slightly more pronounced among the respondents to the oral interview than among the total population.

\section{Measurements}

The socioeconomic status of the respondents is indicated by the highest level of education attained. In the Netherlands, educational level is considered to be a good indicator of socioeconomic status [32]. It has the advantage of being available for both men and women, whether they are in paid employment or not. In addition, its measurement is relatively simple. In our analyses, seven categories were distinguished: primary school only, lower vocational schooling, lower secondary schooling (general), intermediate vocational schooling, intermediate/higher secondary schooling (general), higher vocational schooling, and university.

People were classified according to their smoking habits at the time of the survey. Three categories were established, i.e., current smokers, former smokers, and those who have never smoked. It was found that $35.6 \%$ of survey respondents were current smokers, $34.3 \%$ were former smokers, and $30.1 \%$ had never smoked. In two separate analyses, current smokers were contrasted with never and former smokers, respectively. The first analysis (current versus never smokers) focuses on socioeconomic differences in the proportion of people who have ever started smoking and are still smokers at the time of the survey. In the second series of analyses, current smokers were contrasted with former smokers to indicate socioeconomic differences in smoking cessation.

The (potential) correlates of differences in smoking were classified into categories in order to allow for linear and nonlinear associations with smoking. The cultural factors, all asked for in the oral interview, refer to differences in orientations or attitudes. Three specific factors were examined in this study: locus of control, parochialism, and orientation toward the future. They were all classified into five equal categories.

Locus of control refers to the belief that a person has control over his or her own life. It was measured in this study by means of an adapted unidimensional Dutch questionnaire, based on Rotter's Locus of Control scale [33]. This scale, containing 11 items, had a high internal consistency (Cronbach's $\alpha=0.84$ ). We expected a high score (maximum 55, minimum 11), indicating a more external locus of control, to be related to a higher prevalence of smokers [14,15].

Parochialism refers to an attitude that is relatively closed, narrow, local, and nonscientific [34]. We expected this to be positively related to smoking. A higher score (maximum 25, minimum 5) indicates a more parochial attitude. This factor was measured by a 5-item scale [35]. The internal consistency was good (Cronbach's $\alpha=0.63$ ).

The third cultural factor measured is orientation toward the future. People with a high score on this scale (maximum 20, minimum 4), indicating a lack of orientation toward the future, are probably less likely to incorporate the long-term effects of a certain behavior in their decision to smoke. They are therefore expected to smoke more than people with a low score. We used a 4 -item scale to measure this factor [35]. The internal consistency was low (Cronbach's $\alpha=0.51$ ).

Material factors that were considered are crowding, problems with physical housing and neighborhood conditions, income, financial problems, material and social deprivation, and employment status. All these, except for income and deprivation, were measured in the postal questionnaire.

Crowding was defined as the number of persons per room, and it was coded as a continuous variable. Physical housing conditions were measured by means of a checklist of three items with regard to problems relating to damp, mold, and cold. This variable was classified according to the number of problems reported $(0,1$, 2 , or 3 ). 
Problems with neighborhood conditions were also measured by means of a checklist, containing four items with respect to noise (traffic and neighbors), smell, and vandalism. The answers were classified into four categories $(0,1,2$, or 3 or 4 problems).

Financial problems were indicated by difficulties reported by the respondent relating to the payment of bills, food, rent, etc. The answers were precoded as no problems, some problems, and big problems. Income was indicated by the family net income per month, divided by the number of people that were dependent on that income (with children given less weight than adults). This so-called equivalent income, ranging from between approximately 600 and 6,000 Dutch guilders per month, was divided into five categories of approximately 1,000 guilders.

People were defined as materially deprived if they were not able to afford one or more amenities or expenditures (telephone, basic food, etc.) from a list of six. If people could not engage in three or more of seven activities listed in the questionnaire because of financial reasons (e.g., going out, going on holiday, having friends for dinner), they were classified as socially deprived.

The worse the material conditions (crowding, problems with housing and neighborhood, financial problems, and material and social deprivation), the higher the prevalence of smokers expected [19]. The employment status of the respondent was indicated by the answer on a question regarding his or her main activity. A distinction was made between the paid employed, the unemployed, the long-term work disabled, the (early) pensioned, the housewives $(\mathrm{m} / \mathrm{f})$, and others (mainly students). We anticipated a higher prevalence of smokers among those not in paid employment.

Psychosocial factors were divided into stressors and coping resources, i.e., factors that have an effect on the way people cope with stressors. The stressors studied in the analyses are negative life events and long-term difficulties. The coping resources are social support (emotional and instrumental), neuroticism, and coping styles. All psychosocial factors except for life events were asked for in the oral interview.

Life events were measured by means of a checklist of nine negative life events and were coded as $0,1,2$, and 3 or more life events reported in the previous year.

Long-term difficulties were also measured by means of a self-report questionnaire, an adapted version of a Dutch Long-Term Difficulties Questionnaire [36]. The 18 items in this questionnaire refer to difficulties with living and working conditions (e.g., housing, schooling, work), problems in personal relationships, and health problems of significant others. This variable was coded into five categories $(0,1,2,3, \geqslant 4$ problems in the past year). We expected a higher exposure to the stressors to be related to a higher percentage of smokers [37].

An adapted version of a Dutch questionnaire was used to measure two dimensions of social support [38]: emotional and instrumental support, referring to three significant others. Both subscales had a good internal consistency (emotional and instrumental support Cronbach's $\alpha=0.60$ and 0.67 , respectively). The score on both scales (minimum 0, maximum 30 for emotional support, and 24 for instrumental support) was coded as lack of social support (lowest quintile) versus social support reported. We expected lack of social support to be associated with higher smoking rates [15]. Neuroticism was measured by means of the Eysenck Personality Questionnaire of 12 items [39], which had a high internal consistency (Cronbach's $\alpha=0.81$ ). We expected a higher score on the neuroticism scale (minimum 0, maximum 12) to be associated with a higher chance of smoking [40].

The Utrechtse Coping Lijst was used to measure styles of coping [41]. This questionnaire contains seven subscales, i.e., active problem focusing (minimum 8, maximum 32 ), avoidance behavior (minimum 7 , maximum 28), depressive reaction pattern (minimum 7 , maximum 28), social support seeking (minimum 6, maximum 24), palliative reaction pattern (minimum 6 , maximum 24), disclosure of emotions (minimum 3 , maximum 12), and optimism (minimum 4, maximum 16). The internal consistency of the subscales was good (Cronbach's $\alpha$ ranging from 0.59 to 0.80 ). In particular, we expected a palliative coping style to be related to smoking, as this style is defined as palliating the emotional consequences of stressful situations by, e.g., smoking and drinking. Moreover, smoking is supposed to be positively related to avoidance behavior and a depressive reaction pattern. We expected negative associations for active problem focusing, social support seeking, disclosure of emotions, and optimism.

The variable neuroticism and all coping styles were classified into five equal categories.

Age and sex were considered confounding variables. They might be determinants of smoking and are associated with socioeconomic status. In contrast with the cultural, material, and psychosocial factors, however, age and sex could not be caused by a particular socioeconomic status. They therefore should be considered confounders of the association between socioeconomic status and smoking rather than intermediate variables.

\section{Analyses}

People for whom information on smoking, education, or confounders was missing were excluded, i.e., 70 persons (2.8\% of the study population). All variables except for crowding were coded as dummy variables.

Successively, we investigated whether the (potential) correlates of smoking differences were related to smoking, whether they are associated with socioeconomic status, and to what extent their differential dis- 
tribution statistically accounts for the higher smoking rates among lower socioeconomic groups.

To determine whether the potential correlates were associated with smoking, we fitted logistic regression models, controlling for potential confounders (5-year age groups and sex, and interaction between both variables). The aim was to check whether in our study current smokers differed from never/former smokers with respect to specific cultural, material, or psychosocial factors. The reduction in deviance due to the inclusion of a particular factor was used as an overall statistical measure of its effect.

To describe the distribution of cultural, material, and psychosocial factors as well as current, former, and never smokers among educational levels, we calculated the percentages in each category, directly standardized for age (10-years age groups) and sex.

Logistic regression models were fitted to estimate educational differences in the prevalence of smoking, controlling for potential confounders. The highest educational group was always used as the reference category. The regression coefficients and their standard errors were used to calculate odds ratios and their 95\% confidence intervals. The reduction in deviance due to the inclusion of education was used as an overall statistical measure of its effect.

To estimate the extent to which each set of correlates could statistically account for differences among current smokers, they were added successively to a model containing the educational variable and the confounders only. The percentage reduction in odds ratios for education after adjustment for a set of factors was used as an indicator of its relevance. In order to make the results of the models directly comparable, those respondents who had a missing value on one or more of these factors were excluded from these analyses. An exception was made for those whose response was missing on the income variable. Excluding these respondents significantly changed the estimation of the relevance of other correlates. We therefore included those respondents who had a missing value on income and classified the missing values as a separate category. In the first series of analyses, relating to those who had never smoked, 115 respondents were excluded (7\% of the study population). In the second series (former smokers), 103 respondents were excluded (6\% of the study population).

The analyses were carried out using the GLIM statistical program [42].

\section{RESULTS}

Consistent with the results of other studies, we observed substantial differences in the proportion of smokers (Table 1). The percentage of current smokers steadily increased with decreasing educational level: $50 \%$ of the respondents in the lowest educational
TABLE 1

Prevalence of Current, Former, and Never Smokers by Level of Education, Standardized for Age and Sex, among the Total Population $(n=2,392)$

\begin{tabular}{lccccccc}
\hline & \multicolumn{7}{c}{ Educational Level $^{a}$} \\
\cline { 2 - 8 } & 7 & 6 & 5 & 4 & 3 & 2 & 1 \\
\hline $\begin{array}{c}\text { Percentage } \\
\text { current } \\
\text { smokers } \\
\begin{array}{c}\text { Percentage } \\
\text { former } \\
\text { smokers }\end{array}\end{array}$ & 20.8 & 27.4 & 28.3 & 34.5 & 41.2 & 35.9 & 50.7 \\
$\begin{array}{c}\text { Percentage } \\
\text { never } \\
\text { smokers }\end{array}$ & 49.8 & 40.1 & 42.8 & 37.9 & 33.2 & 34.7 & 24.7 \\
$\begin{array}{c}\text { Number of } \\
\text { respondents }\end{array}$ & 132 & 336.5 & 28.9 & 27.6 & 25.5 & 29.4 & 24.5 \\
\hline
\end{tabular}

${ }^{a} 7=$ high, $1=$ low.

groups were classified as current smokers compared to $20 \%$ in the highest group. The percentage of never smokers was higher among people in higher educational groups. Moreover, among those who had ever smoked (i.e., current plus former smokers), the proportion of former smokers was smaller among lower educational groups. This implies that lower educated people were less inclined to quit smoking. These results are similar to those of another recent Dutch study [43].

The differences between current smokers and never/ former smokers relating to the cultural, material, and psychosocial factors are shown in Tables $2 \mathrm{a}$ and $2 \mathrm{~b}$. Current smokers more frequently had an externally oriented locus of control than both never and former smokers, although that association was only statistically significant for the latter. Furthermore, compared with never and former smokers, current smokers more frequently had a lower score on the scale that indicates a lack of "orientation toward the future" (not significant), as well as on the parochialism scale. This was contrary to our expectations.

Housing conditions (problems with housing and neighborhood conditions, and crowding) did not differ between smokers and never/former smokers. Other material conditions were, however, worse among smokers compared with never and former smokers. Smokers more frequently had lower income and financial problems and were more frequently deprived and not in paid employment.

Moreover, the exposure to stressors was higher among smokers, although this association was only statistically significant when smokers were compared with never smokers in the case of life events. Social support did not differ between smokers and never/ former smokers, whereas smokers more frequently had higher scores on the neuroticism scale than never/ 
TABLE 2a

Univariate Associations between Risk of Being a Current Smoker and Cultural and Material Factors, 25-74 Years of Age, Odds Ratios (OR) and 95\% Confidence Intervals (CI) ${ }^{\alpha}$

\begin{tabular}{|c|c|c|c|c|c|c|}
\hline \multirow[b]{2}{*}{ Factor } & \multicolumn{3}{|c|}{ Smokers versus never smokers } & \multicolumn{3}{|c|}{ Smokers versus former smokers } \\
\hline & OR & $\mathrm{CI}$ & $\begin{array}{l}\text { Significance } \\
\text { red. deviance }\end{array}$ & OR & CI & $\begin{array}{l}\text { Significance } \\
\text { red. deviance }\end{array}$ \\
\hline \multicolumn{7}{|l|}{ Cultural factors } \\
\hline \multicolumn{7}{|l|}{ External locus of control ${ }^{c}$} \\
\hline 1 & 1.00 & & & 1.00 & & \\
\hline 2 & 1.09 & $0.55-2.15$ & & 1.38 & $0.76-2.52$ & \\
\hline 3 & 1.29 & $0.65-2.55$ & & 2.11 & $1.15-3.87$ & \\
\hline 4 & 1.60 & $0.77-3.29$ & & 2.76 & $1.45-5.24$ & \\
\hline 5 & 2.76 & $0.97-7.90$ & $\mathrm{~ns}$ & 4.04 & $1.60-10.20$ & $* *$ \\
\hline \multicolumn{7}{|l|}{ Parochialism $^{c}$} \\
\hline 1 & 1.00 & & & 1.00 & & \\
\hline 2 & 0.99 & $0.40-2.45$ & & 0.65 & $0.25-1.67$ & \\
\hline 3 & 0.95 & $0.39-2.31$ & & 0.78 & $0.31-1.97$ & \\
\hline 4 & 1.03 & $0.42-2.55$ & & 1.04 & $0.41-2.66$ & \\
\hline 5 & 0.81 & $0.31-2.15$ & $\mathrm{~ns}$ & 0.87 & $0.32-2.37$ & $*$ \\
\hline \multicolumn{7}{|c|}{ Lack of orientation toward future ${ }^{c}$} \\
\hline 1 & 1.00 & & & 1.00 & & \\
\hline 2 & 0.77 & $0.45-1.29$ & & 0.56 & $0.35-.90$ & \\
\hline 3 & 0.74 & $0.44-1.25$ & & 0.55 & $0.34-0.89$ & \\
\hline 4 & 0.70 & $0.40-1.20$ & & 0.69 & $0.42-1.14$ & \\
\hline 5 & 0.77 & $0.37-1.61$ & $\mathrm{~ns}$ & 0.56 & $0.29-1.07$ & $\mathrm{~ns}$ \\
\hline \multicolumn{7}{|c|}{ Material factors } \\
\hline \multicolumn{7}{|c|}{ Equivalent income (in Dutch guilders) } \\
\hline $600-1,600$ & 1.00 & & & 1.00 & & \\
\hline $1,600-2,600$ & 0.78 & $0.59-1.02$ & & 0.78 & $0.61-1.00$ & \\
\hline $2,600-3,600$ & 0.61 & $0.44-0.86$ & & 0.52 & $0.38-0.70$ & \\
\hline $3,600-4,600$ & 0.50 & $0.30-0.81$ & & 0.57 & $0.37-0.90$ & \\
\hline $4,600-5,800$ & 0.65 & $0.06-6.62$ & $*$ & 1.68 & $0.27-10.23$ & $* *$ \\
\hline \multicolumn{7}{|l|}{ Financial problems } \\
\hline None & 1.00 & & & 1.00 & & \\
\hline Some & 1.85 & $1.37-2.48$ & & 1.50 & $1.15-1.96$ & \\
\hline Big & 4.16 & $2.14-8.08$ & $* *$ & 3.06 & $1.75-5.34$ & $* *$ \\
\hline \multicolumn{7}{|l|}{ Deprivation } \\
\hline Material & 4.10 & $1.52-11.11$ & $*$ & 2.31 & $1.05-5.09$ & $*$ \\
\hline Social & 3.47 & $1.93-6.24$ & $* *$ & 2.34 & $1.39-3.94$ & $* *$ \\
\hline \multicolumn{7}{|l|}{ Employment status } \\
\hline Paid employment & 1.00 & & & 1.00 & & \\
\hline Unemployed & 1.79 & $0.91-3.50$ & & 1.52 & $0.84-2.72$ & \\
\hline Work disability & 2.17 & $1.31-3.60$ & & 2.18 & $1.43-3.31$ & \\
\hline (Early) retired & 1.37 & $0.76-2.47$ & & 1.76 & $1.07-2.88$ & \\
\hline Housepersons & 1.04 & $0.75-1.45$ & & 1.48 & $1.05-2.10$ & \\
\hline Other & 1.28 & $0.46-3.55$ & $*$ & 2.13 & $0.40-11.48$ & $*$ \\
\hline \multicolumn{7}{|l|}{ Housing conditions } \\
\hline 0 problems & 1.00 & & & 1.00 & & \\
\hline 1 problem & 1.00 & $0.73-1.37$ & & 0.81 & $0.60-1.09$ & \\
\hline 2 problems & 1.45 & $0.92-2.27$ & & 0.95 & $0.64-1.41$ & \\
\hline 3 problems & 1.00 & $0.48-2.10$ & $\mathrm{~ns}$ & 0.93 & $0.47-1.84$ & $\mathrm{~ns}$ \\
\hline \multicolumn{7}{|l|}{ Neighborhood conditions } \\
\hline 0 problems & 1.00 & & & 1.00 & & \\
\hline 1 problem & 0.73 & $0.56-0.96$ & & 0.98 & $0.76-1.26$ & \\
\hline 2 problems & 0.86 & $0.57-1.29$ & & 0.98 & $0.68-1.42$ & \\
\hline$\geqslant 3$ problems & 1.07 & $0.58-1.97$ & $\mathrm{~ns}$ & 0.73 & $0.42-1.26$ & $\mathrm{~ns}$ \\
\hline Crowding (no. persons/room) & 0.96 & $0.85-1.08$ & $\mathrm{~ns}$ & 1.04 & $0.91-1.18$ & $\mathrm{~ns}$ \\
\hline
\end{tabular}

Note. ns, not significant.

${ }^{a}$ Controlled for age, sex, age $\times$ sex.

${ }^{b} P$ value based on the reduction in deviance due to the inclusion of the factor in the model.

${ }^{c}$ Classified into five equal categories $(1=$ lowest score; $5=$ highest score).

$* P<0.05$.

** $P<0.001$. 
TABLE 2b

Univariate Associations between Risk of Being a Current Smoker and Psychosocial Factors, 25-74 Years of Age, Odds Ratios (OR) and 95\% Confidence Intervals (CI) ${ }^{a}$

\begin{tabular}{|c|c|c|c|c|c|c|}
\hline \multirow[b]{2}{*}{ Psychosocial factor } & \multicolumn{3}{|c|}{ Smokers versus never smokers } & \multicolumn{3}{|c|}{ Smokers versus former smokers } \\
\hline & OR & CI & $\begin{array}{c}\text { Significance } \\
\text { red. deviance }\end{array}$ & OR & CI & $\begin{array}{c}\text { Significance } \\
\text { red. deviance }\end{array}$ \\
\hline \multicolumn{7}{|l|}{ Life events } \\
\hline 0 & 1.00 & & & 1.00 & & \\
\hline 1 & 1.32 & $1.03-1.70$ & & 1.00 & $0.80-1.26$ & \\
\hline 2 & 1.41 & $1.02-1.94$ & & 1.13 & $0.84-1.52$ & \\
\hline$\geqslant 3$ & 1.93 & $1.10-3.39$ & $*$ & 1.23 & $0.75-2.01$ & $\mathrm{~ns}$ \\
\hline \multicolumn{7}{|l|}{ Long-term difficulties } \\
\hline 0 & 1.00 & & & 1.00 & & \\
\hline 1 & 1.04 & $0.77-1.40$ & & 1.16 & $0.88-1.54$ & \\
\hline 2 & 0.98 & $0.71-1.36$ & & 1.00 & $0.74-1.34$ & \\
\hline 3 & 1.34 & $0.92-1.96$ & & 1.09 & $0.77-1.52$ & \\
\hline$\geqslant 4$ & 1.52 & $1.07-2.16$ & ns & 1.37 & $0.99-1.88$ & $\mathrm{~ns}$ \\
\hline \multicolumn{7}{|l|}{ Lack of social support } \\
\hline Instrumental & 0.99 & $0.75-1.32$ & ns & 0.83 & $0.64-1.08$ & ns \\
\hline Emotional & 1.00 & $0.75-1.32$ & $\mathrm{~ns}$ & 0.82 & $0.64-1.05$ & $\mathrm{~ns}$ \\
\hline \multicolumn{7}{|l|}{ Neuroticism $^{c}$} \\
\hline 1 & 1.00 & & & 1.00 & & \\
\hline 2 & 1.21 & $0.91-1.61$ & & 0.80 & $0.62-1.04$ & \\
\hline 3 & 1.31 & $0.97-1.78$ & & 1.24 & $0.93-1.66$ & \\
\hline 4 & 1.65 & $1.07-2.54$ & & 1.05 & $0.71-1.55$ & \\
\hline 5 & 2.57 & $1.56-4.22$ & $*$ & 2.61 & $1.54-4.42$ & $* *$ \\
\hline \multicolumn{7}{|l|}{ Coping styles ${ }^{c}$} \\
\hline \multicolumn{7}{|l|}{ Active problem focusing } \\
\hline 1 & 1.00 & & & 1.00 & & \\
\hline 2 & 0.53 & $0.24-1.21$ & & 0.68 & $0.32-1.41$ & \\
\hline 3 & 0.48 & $0.22-1.06$ & & 0.63 & $0.31-1.30$ & \\
\hline 4 & 0.64 & $0.29-1.45$ & & 0.59 & $0.29-1.22$ & \\
\hline 5 & 0.44 & $0.18-1.08$ & $\mathrm{~ns}$ & 0.92 & $0.41-2.05$ & $\mathrm{~ns}$ \\
\hline \multicolumn{7}{|l|}{ Avoidance behavior } \\
\hline 1 & 1.00 & & & 1.00 & & \\
\hline 2 & 0.64 & $0.49-0.85$ & & 0.91 & $0.70-1.16$ & \\
\hline 3 & 0.67 & $0.48-0.93$ & & 1.32 & $1.01-1.74$ & \\
\hline 4 & 0.63 & $0.33-1.18$ & & 0.81 & $0.49-1.36$ & \\
\hline 5 & 0.01 & $0.00-7.06$ & $*$ & 1.28 & $0.53-3.12$ & $*$ \\
\hline \multicolumn{7}{|c|}{ Depressive reaction pattern } \\
\hline 1 & 1.00 & & & 1.00 & & \\
\hline 2 & 1.09 & $0.84-1.41$ & & 1.01 & $0.80-1.28$ & \\
\hline 3 & 1.29 & $0.88-1.88$ & & 1.12 & $0.79-1.60$ & \\
\hline 4 & 3.72 & $1.27-10.92$ & & 2.92 & $1.03-8.25$ & \\
\hline 5 & 1.32 & $0.21-8.16$ & $\mathrm{~ns}$ & 2.25 & $0.36-14.16$ & $\mathrm{~ns}$ \\
\hline \multicolumn{7}{|l|}{ Social support seeking } \\
\hline 1 & 1.00 & & & 1.00 & & \\
\hline 2 & 0.71 & $0.50-1.03$ & & 0.58 & $0.42-0.80$ & \\
\hline 3 & 0.71 & $0.48-1.03$ & & 0.61 & $0.43-0.86$ & \\
\hline 4 & 0.88 & $0.58-1.35$ & & 0.61 & $0.42-0.91$ & \\
\hline 5 & 0.73 & $0.37-1.44$ & $\mathrm{~ns}$ & 0.93 & $0.43-2.01$ & $*$ \\
\hline \multicolumn{7}{|c|}{ Palliative reaction pattern } \\
\hline 1 & 1.00 & & & 1.00 & & \\
\hline 2 & 0.71 & $0.51-1.00$ & & 1.05 & $0.78-1.40$ & \\
\hline 3 & 0.77 & $0.54-1.11$ & & 1.08 & $0.79-1.47$ & \\
\hline 4 & 0.81 & $0.50-1.30$ & & 1.03 & $0.70-1.50$ & \\
\hline 5 & 0.47 & $0.08-2.77$ & $\mathrm{~ns}$ & 1.60 & $0.75-3.43$ & $\mathrm{~ns}$ \\
\hline \multicolumn{7}{|l|}{ Disclosure of emotions } \\
\hline 1 & 1.00 & & & 1.00 & & \\
\hline 2 & 0.90 & $0.65-1.26$ & & 0.61 & $0.44-0.84$ & \\
\hline 3 & 1.12 & $0.79-1.60$ & & 0.56 & $0.40-0.78$ & \\
\hline 4 & 1.37 & $0.89-2.13$ & & 0.70 & $0.47-1.05$ & \\
\hline 5 & 1.52 & $0.64-3.60$ & ns & 0.67 & $0.30-1.49$ & $*$ \\
\hline
\end{tabular}


TABLE 2b-Continued

\begin{tabular}{|c|c|c|c|c|c|c|}
\hline \multirow[b]{2}{*}{ Psychosocial factor } & \multicolumn{3}{|c|}{ Smokers versus never smokers } & \multicolumn{3}{|c|}{ Smokers versus former smokers } \\
\hline & OR & $\mathrm{CI}$ & $\begin{array}{l}\text { Significance } \\
\text { red. deviance }\end{array}$ & OR & $\mathrm{CI}$ & $\begin{array}{l}\text { Significance } \\
\text { red. deviance }\end{array}$ \\
\hline \multicolumn{7}{|l|}{ Optimism } \\
\hline 1 & 1.00 & & & 1.00 & & \\
\hline 2 & 1.00 & $0.53-1.87$ & & 1.35 & $0.78-2.36$ & \\
\hline 3 & 1.36 & $0.75-2.48$ & & 1.35 & $0.81-2.27$ & \\
\hline 4 & 1.24 & $0.66-2.34$ & & 1.37 & $0.78-2.38$ & \\
\hline 5 & 1.11 & $0.54-2.29$ & $\mathrm{~ns}$ & 1.55 & $0.81-2.97$ & $\mathrm{~ns}$ \\
\hline $\begin{array}{l}\text { Note. ns, not signi } \\
{ }^{a} \text { Controlled for a } \\
{ }^{b} P \text {-value based o } \\
{ }^{c} \text { Classified into } \mathrm{f} \\
* P<0.05 \text {. } \\
{ }^{* *} P<0.001 .\end{array}$ & $\begin{array}{l}\text { age } \times \\
\text { ductio } \\
\text { categ }\end{array}$ & $\begin{array}{l}\text { ance due to } \\
=\text { lowest sc }\end{array}$ & $\begin{array}{l}\text { Usion of the fact } \\
\text { highest score). }\end{array}$ & model & & \\
\hline
\end{tabular}

former smokers. These groups also differed with respect to some coping styles. In contrast to our expectations, smokers were less inclined to display avoidance behavior than never smokers, while they did not systematically differ with former smokers in this respect. Moreover, smokers were less inclined to seek social support or to show their emotions, compared with former smokers.

Table 3 shows the distribution of cultural, material, and psychosocial factors across educational levels, using one selected category from each determinant only. Those factors that appeared not to be statistically significantly related to smoking (Table 2 ) have not been included in Table 3.

As expected, the prevalence of an externally oriented locus of control and a parochial attitude was higher among lower socioeconomic groups. In addition (all) adverse material conditions are more prevalent within these groups. The exposure to life events was not consistently related to level of education, although the percentage reporting three or more life events was the highest among those who had primary schooling only. Finally, people in lower educational groups had higher neuroticism scores, were more inclined to use avoidance behavior as a coping style and were less inclined to seek social support. The pattern was irregular for the disclosure of emotions scale.

Figure 1 shows a steep educational gradient associated with the risk of being a smoker compared with the risk of being a never smoker. The odds of current smokers compared with never smokers among people who attained only a primary level of education were more than five times as high as those of persons who attained university education. When smokers were contrasted with former smokers, the gradient was smaller (Fig. 2). Only people in the lowest educational category were significantly less inclined to stop smoking.

Furthermore, these figures show the results of mod- els in which each set of correlates has been controlled for. The difference in odds ratios between these models and the first model, controlling for confounders only, gives an indication of the extent to which the correlates statistically account for differences in smoking.

In an analysis in which the effect of each specific factor had been assessed separately (results not shown), some factors did increase the risks of smoking among lower educational groups. Parochialism can serve as an example. As smokers have a less parochial attitude (Table 2a), and a parochial attitude is more common among the lower socioeconomic groups, its distribution could not account for the higher smoking rates among lower socioeconomic groups. As the aim of these analyses was to identify the factors that are potential determinants of the educational gradient, such factors were excluded from the model. This applies to parochialism, employment status, and coping styles among (never) smokers, and parochialism among (former) smokers. Although cultural factors were not statistically significantly related to smoking among smokers/never smokers, they were included in Fig. 1 in order to make this figure consistent with Fig. 2.

Differences with respect to cultural factors could not statistically account for the educational gradient in smoking when smokers were contrasted with never smokers (Fig. 1). Part of the gradient was accounted for by material factors. Controlling for these factors reduced the odds ratios up to $20 \%$ in the lowest educational levels. The prevalence of financial problems and a low equivalent income, both strongly related to smoking (Table 2a), particularly appeared to account for that effect. The reduction of the odds ratios due to the inclusion of the deprivation indicators was smaller, because of the low percentage of people classified as deprived (Table 3). Finally, psychosocial factors, i.e., the higher exposure to life events and the higher neuroticism scores, were found to be correlates of the socioeco- 


\section{TABLE 3}

Percentage of Persons in Selected Category of Cultural, Material, and Psychosocial Factors, by Level of Education, Standardized for Age and Sex, among the Total Population $(n=2,392)$

\begin{tabular}{|c|c|c|c|c|c|c|c|}
\hline & \multicolumn{7}{|c|}{ Educational level $^{a}$} \\
\hline & 7 & 6 & 5 & 4 & 3 & 2 & 1 \\
\hline \multicolumn{8}{|l|}{ Cultural factors } \\
\hline $\begin{array}{l}\text { External locus of } \\
\text { control: \% in 4th } \\
\text { and 5th category } \\
\text { (highest score) }\end{array}$ & 0.9 & 5.1 & 8.7 & 13.8 & 10.9 & 25.0 & 36.7 \\
\hline $\begin{array}{l}\text { Parochialism: \% in } \\
\text { 4th and 5th cat- } \\
\text { egory (highest }\end{array}$ & 0.9 & 5.1 & 8.7 & 13.8 & 10.9 & 25.0 & 36.7 \\
\hline score) & 13.3 & 14.5 & 14.3 & 31.9 & 30.9 & 52.7 & 56.3 \\
\hline \multicolumn{8}{|l|}{$\begin{array}{l}\text { Mean equivalent } \\
\text { income per } \\
\text { month: } \% \text { with } \\
\text { income }<1,600\end{array}$} \\
\hline Dutch guilders & 8.5 & 16.1 & 14.6 & 35.6 & 25.4 & 55.9 & 69.0 \\
\hline \multicolumn{8}{|l|}{ Financial problems: } \\
\hline \multicolumn{8}{|l|}{ Deprivation } \\
\hline $\begin{array}{l}\% \text { materially de- } \\
\text { prived } \\
\% \text { socially de- }\end{array}$ & 0.4 & 1.2 & 1.1 & 0.2 & 0.7 & 1.4 & 6.8 \\
\hline prived & 0.0 & 1.8 & 1.1 & 1.2 & 2.2 & 4.7 & 11.6 \\
\hline \multicolumn{8}{|l|}{ Employment sta- } \\
\hline $\begin{array}{l}\text { Psychosocial factors } \\
\text { Life events: } \% \\
\text { three or more }\end{array}$ & \multicolumn{4}{|c|}{ Life events: $\%$} & & & \\
\hline \multicolumn{8}{|l|}{ Neuroticism: \% in } \\
\hline $\begin{array}{l}\text { 5th category } \\
\text { (highest score) }\end{array}$ & 0.7 & 2.1 & 2.5 & 3.7 & 4.2 & 4.2 & 14.4 \\
\hline $\begin{array}{l}\text { Coping style: } \% \text { in } \\
\text { 4th and 5th cat- } \\
\text { egory (highest } \\
\text { score): } \\
\text { Avoidance behav- }\end{array}$ & & & & & & & \\
\hline $\begin{array}{l}\text { ior } \\
\text { Social support } \\
\text { seeking } \\
\text { Disclosure of }\end{array}$ & 25.8 & 22.6 & 24.1 & 17.0 & 17.9 & 14.1 & 16.6 \\
\hline emotions & 9.0 & 13.3 & 15.2 & 12.2 & 15.7 & 12.3 & 14.0 \\
\hline
\end{tabular}

${ }^{a} 7=$ high, 1 = low.

nomic differences in smoking. They statistically account for approximately $10 \%$ of the increased risks of lower socioeconomic groups.

The reduction of odds ratios controlling for cultural, material, and psychosocial factors simultaneously was almost as large as the reduction due to controlling for material factors only, implying that psychosocial and material conditions had a large part of their contribution in common. Most of the educational differences remained after we had controlled for all cultural, material, and psychosocial factors.

When smokers were contrasted with former smokers (Fig. 2), controlling for locus of control resulted in a substantial reduction of the risks among the lowest educational groups (ca. 30\%). Also material conditions statistically accounted for a substantial part of the observed gradient. The odds of the lowest educational level were reduced by almost $40 \%$. Financial problems, having a low income, and not being in paid employment especially accounted for the result. Finally, differences in psychosocial factors (neuroticism and coping styles) statistically accounted for part of the increased odds among lower educational groups. After we had controlled for all groups of correlates simultaneously, hardly any differences remained.

\section{DISCUSSION}

We observed higher smoking rates among lower socioeconomic groups-a pattern similar to the findings of other studies in the Netherlands and other western countries, including the United States [2]. The aim of this paper was to identify the cultural, material, and psychosocial correlates of the social pattern of smoking behavior. In our study, cultural factors as well as material and psychosocial factors were found to statistically account for part of the higher smoking rates among lower educational groups, with psychosocial factors being the least important.

Our results might have been biased by nonresponse. This is the case if the association between correlates and smoking on the one hand and educational level on the other is different among respondents and nonrespondents. If, for example, smokers living in adverse conditions were underrepresented among the respondents, the importance of those circumstances as correlates of differences in smoking would have been underestimated. Unfortunately, data on these associations among nonrespondents are not available. Yet we consider serious nonresponse bias to be unlikely, since, as indicated before, the respondents very much resemble the original sample as far as the distribution of socioeconomic characteristics is concerned, and similar socioeconomic differences in smoking were found in the subpopulation considered here compared with the whole study population.

Before interpreting the results of this study, a few issues concerning the cross-sectional character of the data are to be considered. First, as the correlates are measured at the same time as smoking status, their interrelationship does not necessarily have a causal interpretation. It could also reflect an effect of smoking on the correlate. For example, the association between material conditions and smoking is assumed to reflect an effect of the former on the latter, but an effect of smoking on material conditions cannot be ruled out completely. A British study, e.g., indicates an effect of smoking on economic hardship, as money spent on cigarettes, etc., diminishes the available income [19]. Furthermore, smoking may affect orientations, e.g., in the case that failing to quit smoking strengthens a per- 


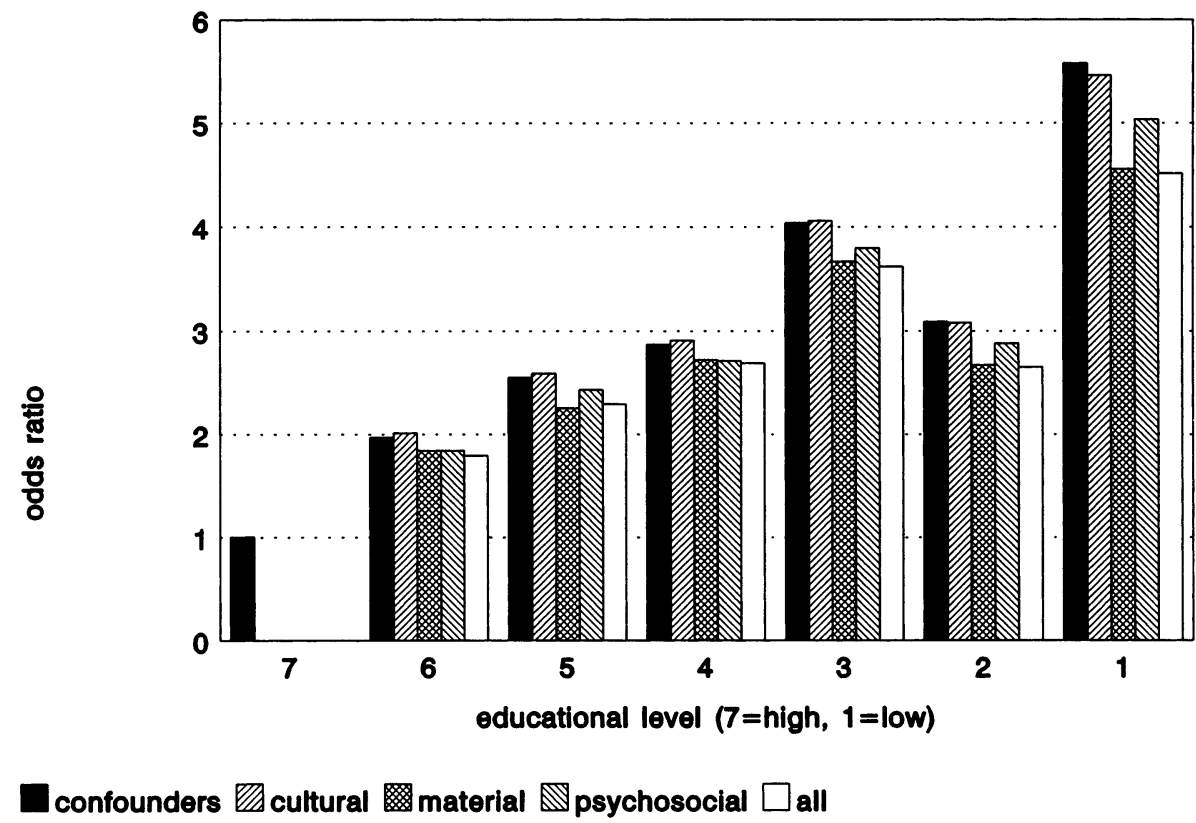

FIG. 1. Association between educational level and the risk of being a current smoker versus a never smoker, controlling for confounders only, and controlling for cultural, material, and psychosocial factors; odds ratios $(n=1,485)$.

son's belief that she/he cannot control her/his life. Second, the correlates may have been measured a long time after respondents had made the decision to start or to quit smoking, especially among the older age groups. When the results are interpreted, the correlates must therefore be considered factors associated with the decision to continue rather than to start or quit smoking.

As a consequence, the correlates as identified in this study are not necessarily causal determinants of socioeconomic differences in smoking. The importance of the correlates for the explanation of the social pattern of smoking should therefore be tested in future research using more powerful data sets.

From the cultural factors included in this study, only locus of control was found to be a correlate of the socioeconomic gradient in smoking. A substantial part of the educational differences in the risk of being a

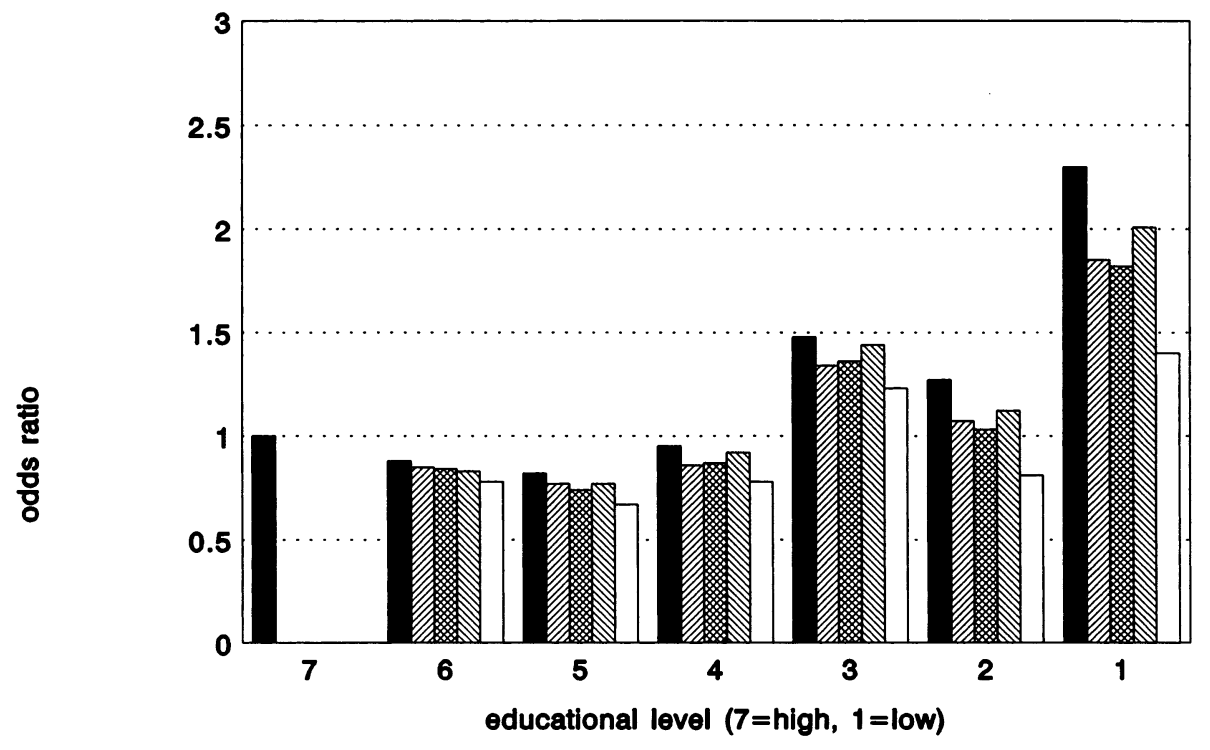

confounders $\mathbb{Q}$ cultural material $\mathbb{Q}$ psychosocial $\square$ all

FIG. 2. Association between educational level and the risk of being a current smoker versus a former smoker, controlling for confounders only, and controlling for cultural, material, and psychosocial factors; odds ratios $(n=1,572)$. 
smoker compared with being a former smoker was found to be associated with the fact that people in lower socioeconomic groups more frequently have an external locus of control. This supports the results of a previous study relating to differences in preventive health behavior [7]. If the association between locus of control and smoking reflects a causal effect, which should be confirmed in more powerful studies, this finding suggests that people from higher educational groups may be more inclined to stop smoking because they more frequently believe that quitting will have a positive effect on their own health.

Furthermore, we observed a more parochial attitude among people in lower socioeconomic groups. We expected this difference in attitude to account for a cultural lag in diffusion of advances across socioeconomic strata [42]. It therefore might have contributed to the higher proportion of quitters in higher socioeconomic groups after research had demonstrated the health risks of smoking. Contrary to our expectations, however, smokers were found to have a less parochial attitude than former/never smokers. This factor therefore could not account for socioeconomic differences in smoking. The same applies to the factor orientation toward the future. These findings probably support the opinion of some authors that the importance of a cultural explanation for differences in health-damaging behavior has been overestimated in the past [12,22]. On the other hand, it may also be the consequence of the rather general character of these measures. Previous studies indicate that the correlation between general measures and specific health behavior is, in general, weak [27]. Other indicators of cultural differences, indicating more specific aspects, probably would have yielded stronger associations. Also the use of cross-sectional data may have contributed to the result, since it may imply that the cultural factors have been measured a long time after most respondents had made the decision to start or to quit smoking.

Material conditions were found to be major correlates of the socioeconomic gradient in smoking. Almost $40 \%$ of the increased risk of being a smoker compared with being a former smoker was found to be associated with unfavorable material conditions. The corresponding figure when current smokers were contrasted with never smokers was $20 \%$. In particular limited financial resources, indicated by the level of available income, financial problems, and deprivation, appeared to account for the effect. Housing conditions were not found to be related to smoking. Further investigation may show whether the absence of this association has to do with the fact that we used rather crude measures to indicate these conditions.

As indicated before, the association between material conditions and smoking does not necessarily reflect a causal association. There is evidence from other studies, however, that material factors have a causal im- pact on smoking. Qualitative studies, most of which were carried out in the United Kingdom, indicate that these conditions may induce people to smoke and hinder people from stopping smoking [24]. Smoking thus may be considered a way of coping with adverse circumstances [3]. On the basis of our results we hypothesize that this mechanism contributes considerably to the higher proportion of smokers in lower socioeconomic groups.

As mentioned in the Introduction, psychosocial factors have not frequently been studied in the context of research on socioeconomic differences in behavior. From the extensive set of psychosocial factors included in this study, neuroticism, coping style, and the exposure to life events were found to be correlates of the educational gradient in smoking. These factors statistically account for a rather small part of this gradient, however. Moreover, the material and psychosocial correlates were found to overlap, which supports the interpretation of the contribution of material conditions in terms of stress and smoking as a way of coping with that stress.

What do these results indicate as to how to reduce the proportion of people in lower socioeconomic status group that smoke?

First, on the basis of our results we hypothesized that people in lower socioeconomic groups are less inclined to stop smoking because they have less belief in the positive effects of quitting on health. This might explain why health education campaigns aimed at making people aware of the health risks of smoking seem to be less effective among lower socioeconomic groups. People in lower socioeconomic groups probably less frequently believe that smoking will be a cause of ill health to them personally, even if they are aware of the health risks of smoking in general. Also coping styles that are associated with smoking were more frequently observed among lower socioeconomic groups. This might indicate that people in lower socioeconomic groups more frequently use smoking as a way of coping with life problems. If our results are confirmed in more powerful studies, these results would indicate that a further reduction of socioeconomic differences in smoking cessation can be found in tailoring smoking cessation programs to the more externally oriented locus of control and the coping styles that are common among lower socioeconomic groups.

Such interventions programs might benefit from further research on the orientations of people in lower socioeconomic groups. It should be studied, for example, why people in lower socioeconomic strata less frequently believe that their behavior might affect health. Illness and premature death might for example be seen as inevitable in these groups, given their high prevalence. In addition, people in lower socioeconomic groups might be less optimistic about the effects of altering their health behavior, since other health risks 
that are beyond their control, such as adverse working or housing conditions, are also more prevalent in these groups.

Yet health promotion campaigns, even if they are tailored to the orientations of specific groups, might not necessarily yield a substantial reduction of smokers among lower socioeconomic groups. This is indicated by the fact that in this study a substantial part of the socioeconomic gradient was associated with the situational contraints that people in lower socioeconomic strata face, such as a low income, financial problems, and unemployment. In combination with the results of other studies, indicating that these constraints should be considered risk factors for smoking and barriers for smoking cessation, we suggest that policy measures aimed at a reduction of smoking should address the living conditions of people in lower socioeconomic groups. The results of our study in particular indicate the potential importance of improving the financial situation and labor market position of lower socioeconomic groups for the reduction of the percentage of smokers among lower socioeconomic groups.

Finally, the results of our study indicate that the efforts to reduce the percentage of smokers among lower socioeconomic groups should include smoking cessation interventions as well as measures that prevent people from taking up smoking. Even if smokers in lower and higher socioeconomic groups are equally inclined to stop smoking, this will not lead to a $100 \%$ reduction of smoking differences between socioeconomic groups. If, in our study population, the prevalence of smokers in lower and higher socioeconomic groups is to become similar, the proportion that quit smoking should be the highest in the lowest socioeconomic groups. It is not realistic to expect this situation to occur, given the distribution of material and cultural factors, especially, across socioeconomic groups. Therefore, eliminating socioeconomic differences in smoking in future populations may be achieved only if we can equally induce people in lower and higher socioeconomic groups not to start smoking in the first place. The fact that intervention strategies aimed at preventing people from taking up health-damaging behavior seem to be more effective than interventions aimed at behavioral change supports this view $[27,49]$.

We hope that others will try to confirm our findings using more powerful data sets. This should indicate whether the correlates of socioeconomic differences in smoking as identified here are causal determinants of the social pattern of smoking. Moreover, further research should pay attention to some determinants of smoking that were omitted in this study, including social pressure and smoking behavior of peers $[27,45-$ 48]. Younger age groups should be included too, since most smokers start during adolescence, and socioeconomic differences in smoking already exist in that age group $[48,49]$. A more detailed examination of the backgrounds of the socioeconomic gradient in smoking can provide information that should enable us to reduce smoking rates more effectively.

\section{ACKNOWLEDGMENTS}

The authors thank Isabel Sivera van der Sluys for carrying out factor analyses and reliability analyses. The LS-SEHD is supported financially by the Prevention Fund, and the Ministry of Public Health Welfare and Sport. It forms part of the GLOBE study (Gezondheid en Levensomstandigheden Bevolking Eindhoven en omstreken). The GLOBE study is being carried out by the Department of Public Health of Erasmus University Rotterdam, in collaboration with the Public Health Services of the city of Eindhoven, the region of Geldrop-Valkenswaard, and the region of Helmond. The GLOBE study as a whole is supported financially by the Prevention Fund (Praeventiefonds), the Ministry of Public Health, Welfare and Sport, the Sick Fund Council (Ziekenfondsraad), the Netherlands Organization for the Advancement of Research, Erasmus University Rotterdam, and the National Commission for the Chronically Ill.

\section{REFERENCES}

1. Reek J van, Adriaanse H. Cigarette smoking and cessation rates by level of education in five western countries. Int J Epidemiol 1988;17:99-103.

2. Pierce JP. International comparisons of trends in cigarette smoking prevalence. Am J Public Health 1989;79:152-7.

3. Graham H. Cigarette smoking: a light on gender and class inequality in Britain? J Soc Policy 1995;24:509-27.

4. Marmot MG, Rose G, Shipley M, Hamilton PJS. Employment grade and coronary heart disease in British civil servants. J Epidemiol Community Health 1978;32:244-9.

5. Pocock SJ, Shaper AG, Cook DG, Philips AN, Walker M. Social class differences in ischaemic heart disease in British men. Lancet 1987;2:197-201.

6. Liu K, Cedres LB, Stamler J, et al. Relationship of education to major risk factors and death from coronary heart disease, cardiovascular diseases and all causes. Circulation 1982;66:130814.

7. Pill R, Peters TJ, Robling MR. Social class and preventive health behaviour: a British example. J Epidemiol Community Health 1995;49:28-32.

8. Morgan M, Calnan M, Manning N: Sociological approaches to health and medicine. London: Croom Helm, 1985.

9. Grusky DB, editor. Social stratification. Class, race and gender in sociological perspective. Boulder (CO): Westview Press, 1994.

10. Susser M, Watson W, Hopper K. Sociology in medicine. New York/Oxford: Oxford Univ. Press, 1985.

11. Calnan M, Johnson B. Health, health risks and inequalities: an exploratory study of women's perceptions. Soc Health Illness 1985;7:55-75.

12. Pill R, Stott NC. Preventive procedures and practices among working class women: new data and fresh insights. Soc Sci Med 1985;21:975-83.

13. Williams SJ. Theorising class, health and lifestyles: can Bourdieu help us? Soc Health Illness 1995;17:577-604.

14. Blaxter M. Health and lifestyles. London: Routledge, 1990.

15. Dean K. Self-care components of lifestyles: the importance of gender, attitudes and the social situation. Soc Sci Med 1989;29: 137-52.

16. Calnan M. Control over health and patterns of health-related behaviour. Soc Sci Med 1989;29:131-6.

17. Halfens RFG. Locus of control: beheersingsoriëntatie in relatie 
tot ziekte- en gezondheidsgedrag. Maastricht: Rijksuniversiteit Limburg, 1985. [in Dutch]

18. Graham H. When life's a drag. Women, smoking and disadvantage. London: HMSO, 1993.

19. Marsh A, McKay S. Poor smokers. London: Policy Studies Institute, 1994.

20. Graham H. Gender and class as dimensions of smoking behaviour in Britain: insights from a survey of mothers. Soc Sci Med 1994;38:691-8.

21. Williams DR. Socioeconomic differentials in health: A review and redirection. Soc Psych Q 1990;53:81-99.

22. Whitehead M. The health divide. In: Townsend P, Davidson N, Whitehead M, editors. Inequalities in health. London: Penguin, 1988:216-381.

23. Gottlieb NH, Green LW. Life events, social network, life-style and health: an analysis of the 1979 national survey of personal health practices and consequences. Health Educ Q 1984;11:91105.

24. Graham H. Women's smoking and family health. Soc Sci Med 1987;25:47-56.

25. Robbins MC, Kline A. To smoke or not to smoke: a decision theory perspective. Soc Sci Med 1991;33:1343-7.

26. Kessler RC, Cleary PD. Social class and psychological distress. Am Soc Rev 1980;45:463-78.

27. Stroebe W, Stroebe MS. Social psychology and health. Buckingham: OUP, 1995.

28. Griffin KW, Friend R, Eitel P, Lobel M. Effect of environmental demands, stress, and mood on health practices. J Behav Med 1993;16:643-61.

29. Broman CL. Social relationships and health-related behavior. J Behav Med 1993;16:335-50.

30. Mackenbach JP, Mheen H van de, Stronks K. A prospective cohort study investigating the explanation of socio-economic inequalities in health in the Netherlands. Soc Sci Med 1994;38: 299-308.

31. Meer JBW van der, Looman CWN, Mackenbach JP. Sociaaleconomische verschillen in medische consumptie. Rotterdam: Erasmus University, 1993. [in Dutch]

32. Berkel van-van Schaik AB, Tax B. Naar een standaardoperationalisatie van sociaal-economische status voor epidemiologisch en sociaal-medisch onderzoek. Rijswijk: Ministerie van WVC, 1990. [in Dutch]
33. Andriessen JHTH. Interne of externe beheersing. Ned Tijdschr Psych 1972;27:173-8.

34. Moody PM, Gray RM. Social class, social integration, and the use of preventive health services. In: Jaco EG, editor. Patients, physicians and illness. New York: The Free Press, 1972.

35. Tax LCMM, Waarden, mentaliteit en beroep. Lisse: Swets \& Zeitlinger, 1982. [in Dutch]

36. Hendriks AAJ, Ormel J, Willige G van de. Langdurige moeilijkheden gemeten volgens zelfbeoordelingsvragenlijst en semigestructureerd interview. Gedrag en Gezondheid 1990;18:27383. [in Dutch]

37. Conway TL, Ward HW, Vickers RR, Rahe RH. Occupational stress and variation in cigarette, coffee, and alcohol consumption. J Health Soc Behav 1981;22:155-65.

38. Tilburg TG van. Verkregen en gewenste ondersteuning in het licht van eenzaamheidservaringen. Amsterdam: Vrije Universiteit, 1988. [in Dutch]

39. Eysenck SB, Eysenck HL, Barret P. A revised version of the psychotism scale. Perspect Individ Differ 1985;6:21-9.

40. Vingerhoets AJJM, Croon M, Jeninga AJ, Menges LJ. Personality and health habits. Psychol Health 1990;4:333-42.

41. Schreurs P, Tellegen B, Vromans ISY, van de Willige G. De ontwikkeling van de Utrechtse Coping Lijst. Utrecht: Vakgroep Klinische Psychologie, Rijksuniversiteit, 1983. [in Dutch]

42. Baker RJ, Nelder JA. GLIM manual (Release 3). Oxford: Numerical Algorithms Group, 1978.

43. Hoeymans N, Smit HA, Verkleij H, Kromhout D. Sociaaleconomische status, levensstijlfactoren, biologische risicofactoren en hart-en vaatziekten. Bilthoven: RIVM, 1993. [in Dutch]

44. Blaxter M. Social class and health inequalities. In: Carter CO, J Peel, editors. Equalities and inequalities in health. London: Academic Press, 1976.

45. Warburton DM, Revell AD. Thompson DH. Smokers of the future. Br J Addict 1991;86:621-5.

46. Goddard E. Why children start smoking. London: HMSO, 1990.

47. Castro FG, Maddahian E, Newcomb MD, Bentler PM. A multivariate model of the determinants of cigarette smoking among adolescents. J Health Soc Behav 1987;28:273-89.

48. Vries $\mathrm{H}$ de. Socio-economic differences in smoking: Dutch adolescents' beliefs and behaviour. Soc Sci Med 1995;41:419-24.

49. Chatrou M. Determinants of smoking and smoking prevention in Dutch adolescents [Dissertation]. Leiden: Univ. Press, 1992 